\title{
Mars: Troughed Terrain ${ }^{1}$
}

\author{
Robert P. Sharp \\ Division of Geological and Planetary Sciences, California Institute of Technology \\ Pasadena, California 91109
}

\begin{abstract}
An assemblage of huge parallel troughs, individually up to $200 \mathrm{~km}$ wide and hundreds of kilometers long, forms a belt $500 \mathrm{~km}$ wide extending for $2700 \mathrm{~km} \mathrm{E} 15^{\circ} \mathrm{S}$ through the Tithonius Lacus-Coprates region of equatorial Mars. Some troughs are closed depressions more than $3 \mathrm{~km}$ deep, and the maximum trough depth may approach $6 \mathrm{~km}$. These troughs, heading just southeast of the huge Tharsis volcanic ridge, are transitional westward into a festoon of $U$-shaped hollows and eastward into chaotic and fretted terrain. Parallel linear chains of rimless pits and shallow graben on the adjacent cratered upland suggest structural control of trough development by fractures in the Martian crust. Trough walls show scarring by slides, slumps, and $U$-shaped avalanche chutes. Some are dissected into narrow sharp anastomosing ridges reminiscent of badland topography. Dendritic tributaries extend $150 \mathrm{~km}$ into the bordering upland. These tributaries and the mass movements causing recession of trough walls are attributed to a sapping process possibly involving the evaporation or melting of exposed ground ice. Trough floors range from chaotically rough to rolling and subdued. They are not smoothly graded. In one instance layered materials, possibly $2 \mathrm{~km}$ thick, compose a dissected trough floor tableland. Most troughs may be partly filled by such deposits. The major problem of trough genesis involves disposal of about $2 \times 10^{6} \mathrm{~km}^{3}$ of material. Running water, solution, deflation, and ground ice deterioration all appear to have significant limitations as the sole or principal agent of trough formation. Subsidence caused by magma withdrawal to supply the extensive nearby volcanic fields or the spreading of crustal plates are both quantitatively adequate. Crustal spreading would have significant implications concerning the conditions and the behavior of the Martian interior, and the lack of any obvious subduction zones would imply planetary expansion. In our ignorance concerning Mars both magma withdrawal and crustal spreading merit continued consideration in respect to trough formation, with some favor to the former because of the obvious large-scale Martian volcanism. Ground ice may have played a significant subsidiary role through sapping to produce extensive recession of trough walls.
\end{abstract}

One of the spectacular revelations of the Mariner 9 pictures was the assemblage of huge troughs in the Tithonius Lacus-Coprates region of equatorial Mars. These features represent a significant phase in the evolution of the planet, and their interpretation, although necessarily highly speculative, is justified by the potential for indicating something of the nature of surficial and internal conditions and processes of Mars.

Although the terms canyons [McCauley et $a l ., 1972]$ and canyonland have been widely used for these features and this terrain, presumably because of a similarity to the deeply dissected high plateaus of the western United States,

\footnotetext{
${ }^{1}$ Contribution 2265, Division of Geological and Planetary Sciences, California Institute of Technology, Pasadena, California.
}

Copyright (C) 1973 by the American Geophysical Union. these designations do not appear particularly appropriate. Some of the canyons are actually closed depressions (Figure 1a); others, although joined together, do not compose a normally integrated trunk and tributary system, and their floors are not smoothly graded. The term canyon also implies a genesis by running water [Howell, 1957]. For these reasons, the individual features are herein termed troughs, and the area they inhabit is called troughed terrain, terms designed to be purely descriptive without genetic implications. This is a brief and preliminary report on these features, which will undoubtedly be a subject of more detailed future treatment.

\section{Salient Facts Concerning Troughed Terrain}

Geographical location. Troughed terrain occupies an equatorial belt extending from about 


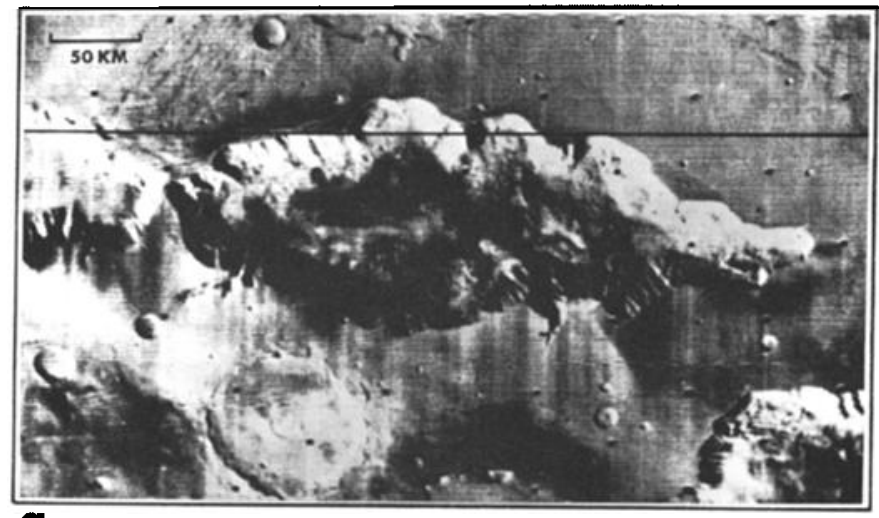

a

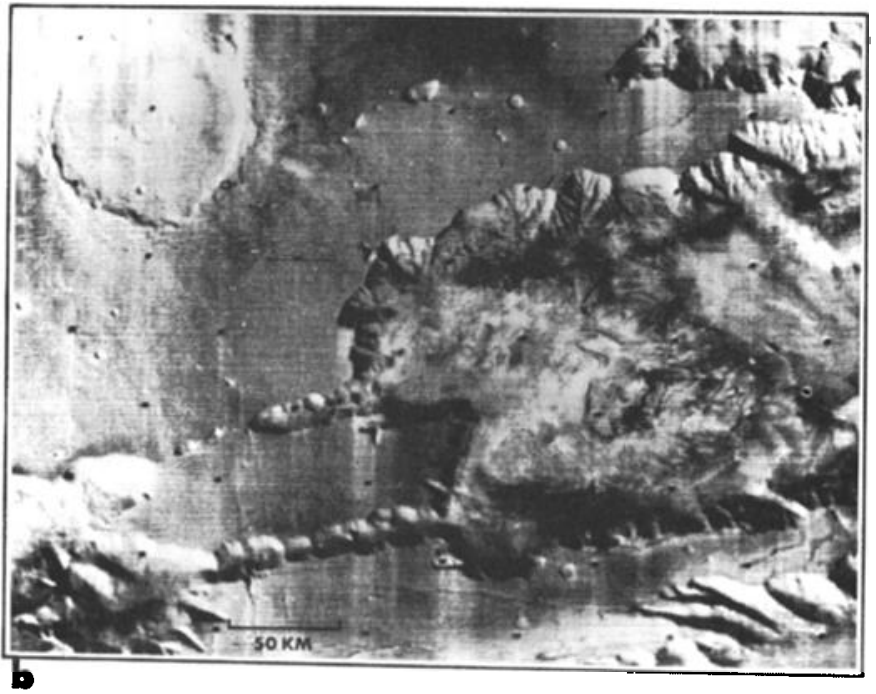

Fig. 1. (a) Closed trough $350 \mathrm{~km}$ long and estimated more than $3 \mathrm{~km}$ deep; located $0.2^{\circ} \mathrm{S}, 76.5^{\circ} \mathrm{W}$. (MTVS 4193-54, DAS 07399108.) (b) Blunt-ended trough with small troughs presumably developed from pit chains continuing beyond; located $4.9^{\circ} \mathrm{S}, 77^{\circ} \mathrm{W}$. The swirllike markings on the floor may indicate dissection of layered floor deposits. This photo overlaps the south edge of (a). (MTVS 4193-45, DAS 07398758.)

$0^{\circ}$ to $16^{\circ} \mathrm{S}$ latitude between longitudes $45^{\circ}$ and $90^{\circ}$. This is largely within the classical Martian dark areas of Tithonius Lacus, Coprates, and the westernmost part of Aurorae Sinus. It is now clear that some of the dark markings on Mars earlier recognized by earth-based telescopic observations, for example, Coprates and Agathodaemon, lie within this belt of troughs. Some expression of these features has thus been seen from the earth, but too dimly to perceive their true nature.

Dimensions. Individual troughs range up to $200 \mathrm{~km}$ wide and several hundred kilometers long. Cumulatively, the troughs compose a belt with a maximum width of $500 \mathrm{~km}$ and a length of $2700 \mathrm{~km}$. Simple calculations, assuming conservative average wall slopes of $10^{\circ}$, indicate maximum depths in excess of $3 \mathrm{~km}$, photogrammetrical data yield a similar value [Blasius, 1973], earth-based radar measurements suggest $4.5 \mathrm{~km}$ [Pettengill et al., 1971], and ultraviolet spectrometer data have been interpreted as indicating $6 \mathrm{~km}$.

Planimetric geometry. The trend of most troughs, as well as the belt they compose, is parallel on a bearing $\mathbf{E} 15^{\circ} \mathrm{S}$. In detail, trough walls are highly irregular with projecting points, sharp indentations, arcuate scallops, and large open embayments. A few trough ends are acute; but most are blunt, and a few are almost rec- 
tangular (Figure 1b). Some troughs are wholly closed depressions (Figure $1 a$ ), with a vertical closure estimated in excess of $3 \mathrm{~km}$, assuming a conservative wall slope of $10^{\circ}$. The floors of adjoining troughs do not appear to be graded along a continuous profile.

Trough floors. Large parts of trough floors look topographically featureless at a resolution of 1-2 km. However, narrow-angle pictures with much greater resolution show that they are mostly a chaotic jumble of angular forms (Figure $2 b, c)$, irregularly knobby, or marked by rounded rolls and hummocks (Figure $3 b$ ). Albedo variations on trough floors are stronger, more numerous, and geometrically more complex than on the adjoining upland. Complex swirl patterns are locally visible (Figure $1 b$ ). Only a small number of bowl-shaped craters $(0.5-1 \mathrm{~km})$ are seen on trough floors in addition to a few larger (to $30 \mathrm{~km}$ ) indistinct circular forms. The possibility that the troughs may be fossil features, albeit young fossils, with respect to the current Martian environment needs to be kept in mind. If this were so, the
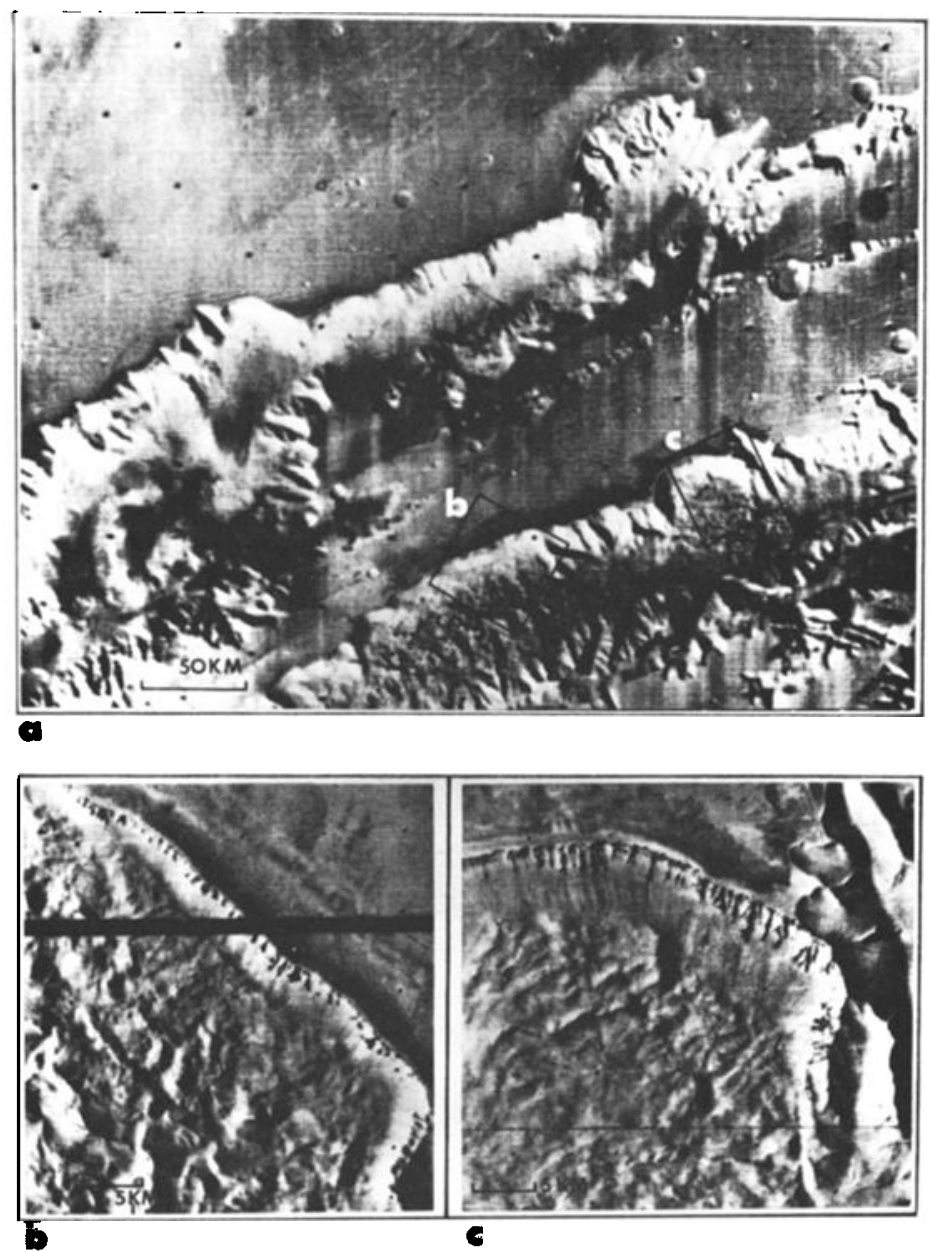

Fig. 2. (a) Adjacent troughs showing variations in wall sculpture and an intervening parallel pit chain. (MTVS 4191-45, DAS 07326798.) (b) Close-up view of part of the large slide area on the north wall of the lower trough. (MTVS 4273-16, DAS 10132999.) (c) Another slide mass and scar on the north wall of the same trough. The irregular terrain on the floor below is typical landslide topography. The height of scarp is at least 1.5-2.3 km. (MTVS 4275-24, DAS 10204679.) 
present irregular topography of trough floors may not represent the conditions at the time the troughs were formed.

Rising as much as $3 \mathrm{~km}$ [Blasius, 1973] above the floors of several troughs are narrow spinelike intratrough ridges, with widths of up to $20 \mathrm{~km}$ and lengths of up to $300 \mathrm{~km}$ (Figures $3 b$ and $4 b$ ). In one place a flat top tableland, 90 $\mathrm{km}$ long and $35 \mathrm{~km}$ wide, rises more than 2 $\mathbf{k m}$ above a trough floor (Figure $5 a$ ). The topography and markings on its flanks, revealed by narrow-angle pictures, suggest near-horizontal layered materials (Figure $5 b$ ). The lower slopes, starting at a uniform level, are intimately rilled and slide scarred. Irregular, but conformable, albedo patterns elsewhere on trough floors (Figure 1b) may indicate similar deposits. Such deposits and their dissected condition indicate a complex history of trough floor evolution.

Trough walls. A sharp brink separates trough walls from the upland surface, and below this rim the walls are usually steepest (Figures 2b,c and 6b). The upper parts of many walls are scarred by $U$-shaped chutes that descend fully developed from the brink (Figures 2b,c and 4b). These chutes give way

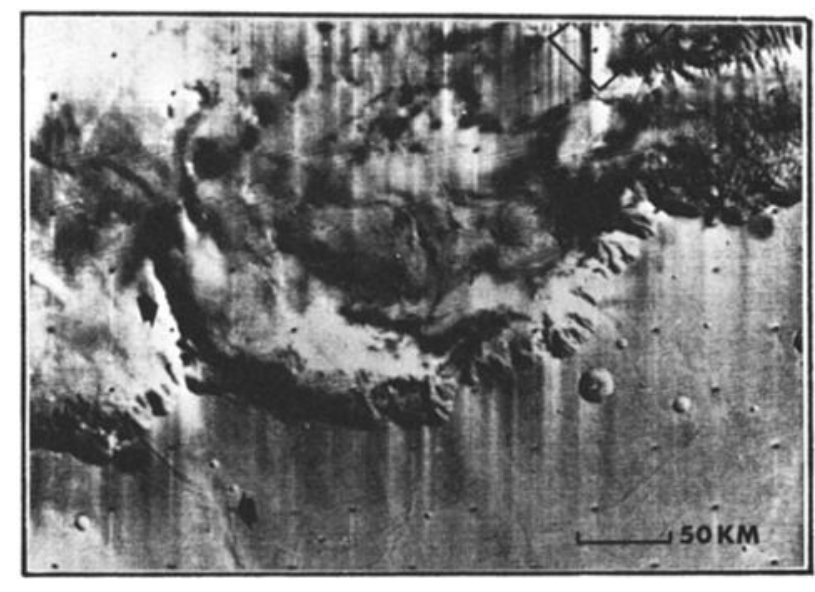

a

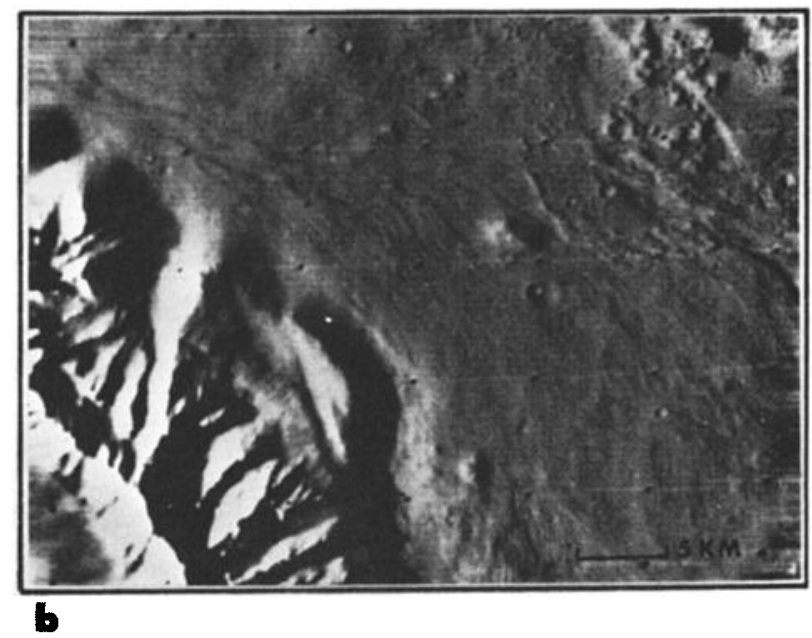

Fig. 3. (a) Projecting spur (arrow marked) may represent a resistant dike left in relief by wall recession. The continuation on the upland is indicated by low ridge. (MTVS 4195-33, DAS 07470578.) (b) Details of floor morphology of above trough within area marked near the upper right. The rough terrain at the lower left is part of intratrough ridge. The unusual number of small bowl-shaped craters suggests some antiquity, and the sinuous linear rounded ridges are suggestive of mass movement. (MTVS 4295-36, DAS 12865578.) 


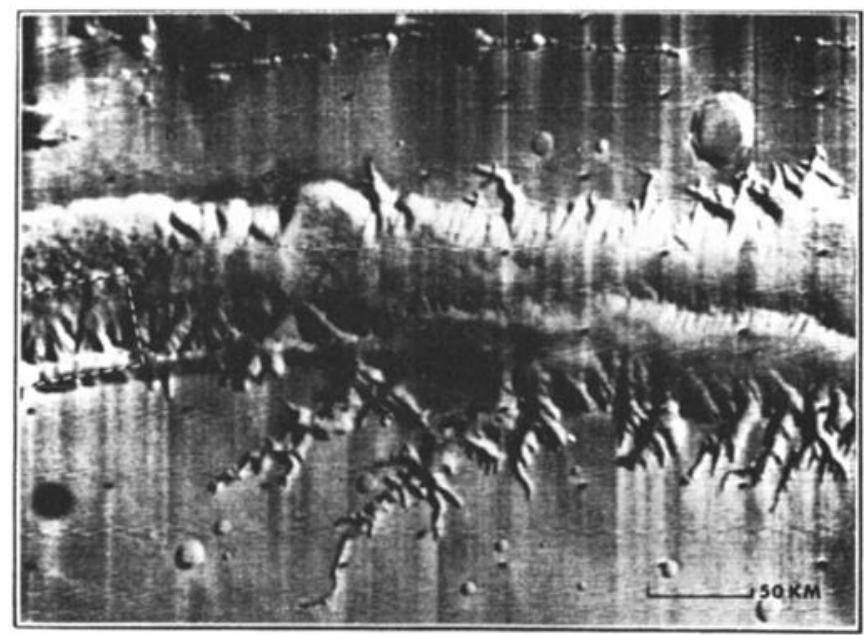

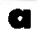

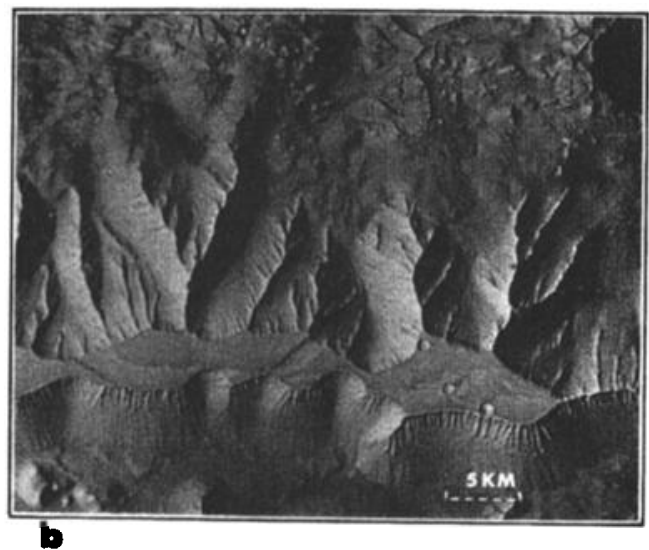

Fig. 4. (a) Segment of a trough, at $7.75^{\circ} \mathrm{S}, 843^{\circ} \mathrm{W}$, showing parallel pit chain (upper edge), intratrough ridge (middle right), and dendritic tributaries (lower half). (MTVS 414487, DAS 05851968.) (b) Specially processed narrow-angle view of intratrough ridge showing irregular slide topography at the top, anastomosing pattern of sharp ridges on the far flank, remnant of cratered upland surface and curving fault graben on the top, and $U$-shaped avalanche chutes below the rim on the near (south) side. (MTVS 4191-42, DAS 07326763.)

below either to smooth slopes or to an anastomosing complex of sharp ridges separated by broad open swales or gullies, somewhat resembling but not wholly comparable in detail to badland topography (Figure $6 b$ ). The flanks of intratrough ridges are similarly sculptured (Figure $4 b$ ). Some long slopes display all three characteristics: $U$-shaped chutes, smoothness, and anastomosing ridges.

Aside from a greater coherence possibly suggested by the steepness below the rim, layering is not generally seen in materials composing most trough walls. This may be partly a matter of resolution, since faint suggestions of near- horizontal layering are seen in one specially treated picture of an intratrough ridge (Figure 4b). Knobs, spurs, and other irregularities on the walls suggest that other types of inhomogeneity exist within the wall materials. One prominent spur, projecting $75 \mathrm{~km}$ from the wall, may mark the location of a dike (Figure $3 a$ ), and the shape and arrangement of some narrow spurs and adjacent reentrants suggest local structural control, probably fractures.

Impressive among wall features are the numerous large arc-shaped reentrants cut back into the upland with a minimum headwall height of 1.5-2 km (Figure 2b,c). At their 


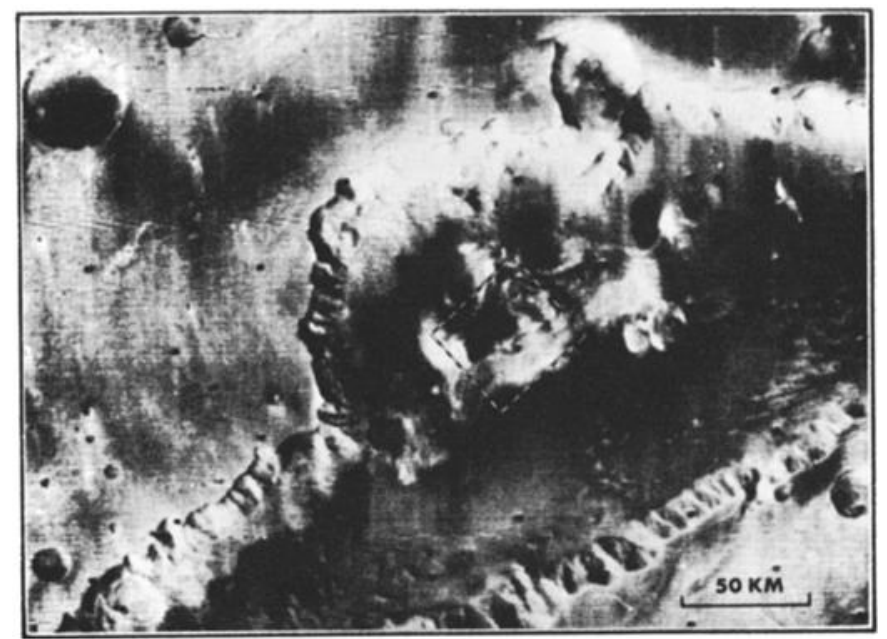

a

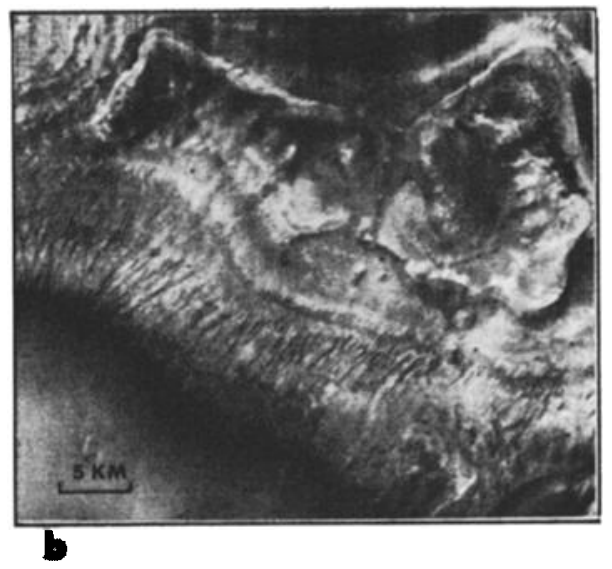

Fig. 5. (a) Trough with swirl pattern on floor, located $6.2^{\circ} \mathrm{S}, 49.5^{\circ} \mathrm{W}$. (MTVS 4199-45, DAS 07614498.) (b) Close-up view showing that the swirl pattern is a dissected tableland of layered deposits. Rillelike dissection of lower slopes starts at a specific layer and strongly resembles erosion by fluid seepage. The height of tableland may be $2 \mathrm{~km}$. (MTVS 4241-59, DAS 09017619.)

feet are accumulations of jumbled blocky debris. Arc-shaped rotated blocks are also seen on the face of some trough walls.

Extramarginal features and relationships. Although not one of the most heavily cratered parts of Mars, the upland surrounding the troughs has a moderate density of craters of up to $50 \mathrm{~km}$ diameter. Large craters appear to have served as sites for the initiation of some small troughs that are generally geometrically discordant with the prevailing trend. Other discordant troughs, up to $100 \mathrm{~km}$ long and an estimated $0.5-1 \mathrm{~km}$ deep, have also formed within the upland seemingly without crater association.

Aside from two cones with central craters adjacent to a trough near $10^{\circ} \mathrm{S}$ and $55^{\circ} \mathrm{W}$, features obviously of volcanic origin are not scattered through the belt of troughs. However, the eastern edge of the largest recent volcanic field on Mars lies but a short distance northwest of the troughed terrain.

On the upland, in the vicinity of troughs, linear chains of pits (Figures $4 a$ and $6 a$ ) parallel the troughs or extend beyond their blunt ends (Figure 1b). The pits are of circular to 
irregular outline, smooth walled, narrow bottomed, and seemingly rimless. Individual pits, 1-15 km across, are estimated to be up to 0.5 $\mathrm{km}$ deep, and pit chains attain lengths up to 350 $\mathrm{km}$. As the pits grow, they develop elongation and become integrated along the chain, eventually producing a small trough with strongly scalloped walls (Figure 6a). Pit chains are not unique to the troughed area; excellent examples are abundantly seen in the volcanic area to the northwest.

A complex of shallow graben 1-5 km wide and up to $100 \mathrm{~km}$ long, locally accompanied by low horsts of similar dimensions, traverses the upland adjacent to some troughs. In places these features parallel the troughs, but elsewhere they are discordantly truncated by trough walls. At least some of the graben are old enough to be cut by craters of up to $10 \mathrm{~km}$ in diameter. Curiously, within the troughed area, fractures bounding graben and horsts have not developed pits, and this is true elsewhere on Mars, as at $35^{\circ} \mathrm{N}, 105^{\circ} \mathrm{W}$.

In the sector between $77^{\circ}$ and $87^{\circ} \mathrm{W}$, principally but not exclusively on the south side of a trough, are a number of steep walled, angular,

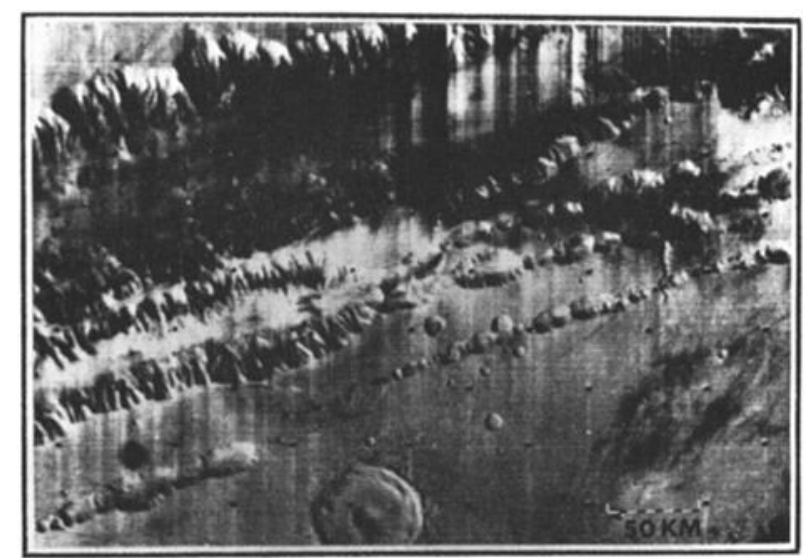

a

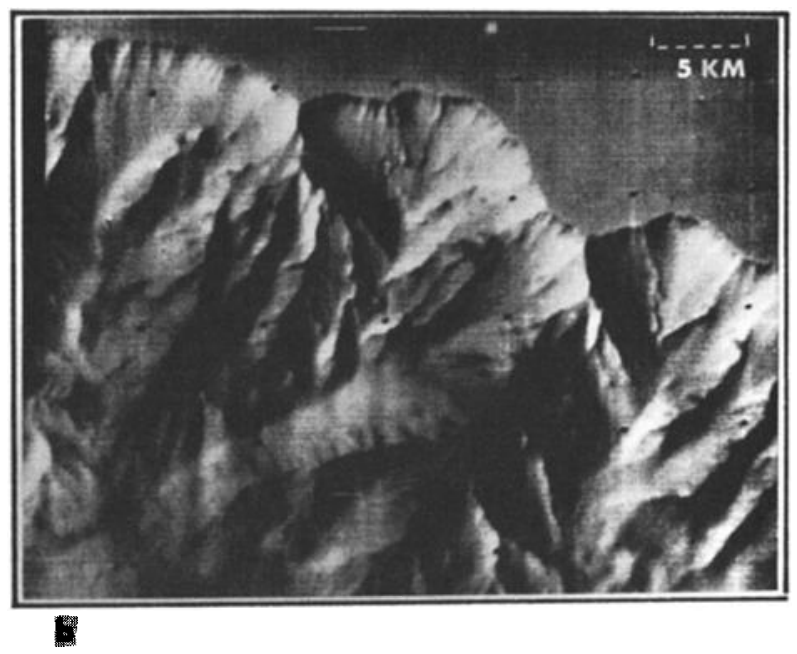

Fig. 6. (a) Large trough with smaller parallel troughs and prominent pit chain; located $14.8^{\circ} \mathrm{S}, 62.7^{\circ} \mathrm{W}$. (MTVS $4197-33$, DAS 07542468.) (b) Close-up view of far (north) wall of the above trough showing badlandlike pattern of anastomosing ridges of a type possibly produced by dry mass movements but more commonly attributed on the earth to fluvial erosion. (MTVS 4197-36, DAS 07542503.) 
dendritic tributaries extending up to $150 \mathrm{~km}$ back from the rim (Figure $4 a$ ). These tributaries decrease in size headward from a maximum width of $10 \mathrm{~km}$ and a depth of perhaps 1 $\mathrm{km}$ at the trough edge. The trunk tributaries and their secondary and tertiary branches display a strong angular pattern, presumably reflecting control by fractures, essentially none of which are paralled to the trend of the troughs. Small-scale pitting is seen at the heads of some tributaries.

The troughed terrain passes westward directly into a festoonlike complex of linear $U$-shaped hollows and, by transition, eastward into the principal area of chaotic terrain and into large areas of smooth lowlands bounded by abrupt cliffs, known as fretted terrain [Sharp, 1973].

\section{INFERENCES}

The parallelism of individual troughs and their walls, of associated pit chains, and of horsts and graben, all bearing about $\mathrm{E} 15^{\circ} \mathrm{S}$, implies strong control by structures in the Martian crust, presumably fractures.

Widening and extension of troughs by some mechanism of wall recession, rather than solely by pulling apart, are strongly suggested by blunt trough ends. Acute ends would be anticipated if the troughs had formed only by spreading, unless transform faulting has occurred, for which there is no independent evidence. Spurs projecting as much as $75 \mathrm{~km}$ inward from trough walls also indicate extensive wall recession.

The scalloped and embayed configuration of the trough rim, its sharpness, $U$-shaped chutes, arc-shaped blocks on trough walls, and local piles of jumbled debris on trough floors below deep wall embayments indicate that mass movements in the form of slides, slumps, and probably debris avalanches have been a major agent of wall sculpturing and presumably of wall recession. The dendritic tributaries extending up to $150 \mathrm{~km}$ into the upland imply the action of a sapping process working headward along different sets of fractures. This same sapping process may be a principal cause of mass movements on trough walls and, therefore, of wall recession.

Chains of unrimmed pits appear to develop by collapse along fractures, owing to removal of underlying support. Continuing collapse causes growth, and, once the pits attain a moderate size and depth, the sapping process may become effective, causing them to enlarge more irregularly and to merge longitudinally to create a small trough with strongly scalloped walls.

The occurrence of at least one 2-km-thick accumulation of layered materials on a trough floor (Figure $5 b$ ) suggests that other troughs may be partly filled with similar material. The layering is much too strong for this to be simply a slumped wall block. The agent of dissection of the deposits is not known, but the potential for dissection could be created by subsidence of a nearby floor segment or the integration of two trough floors lying at different levels.

The small number of craters on trough floors implies either a youthful age or an activity that destroys craters. The troughs cannot be very old, or they would show greater signs of modification. They appear to be among the younger features of the Martian surface, even though they may be fossil or relict with respect to the present surface environment.

\section{Genesis of Troughs}

The following is a speculative scenario as to how the troughs may have been initiated and how they subsequently grew to their present form and size. The initial event appears to have been the formation of parallel fractures trending about $\mathrm{E} 15^{\circ} \mathrm{S}$. Two types of fractures or two sets of different age seem to have formed. One set, seemingly older and possibly shallow, experienced movements creating shallow graben and low horsts. The second set, possibly of greater depth, experienced removal of underlying support, which created chains of pits by collapse. Downward movement of debris could have been facilitated by a highly fragmented condition resulting from antecedent impacting. The pits grew larger, partly by further collapse, possibly aided by wall recession through sapping, until they merged longitudinally along the fracture to create a small trough with highly scalloped walls (Figures 1b, 6a). Continued subsidence, sapping, and wall recession by mass movements widened these troughs until they merged laterally, creating still larger troughs. The evidence for such lateral mergers is provided by spinelike intratrough ridges, which represent remnants of the septa originally 
separating adjacent troughs. The troughs also grew longitudinally by wall recession, and blunt trough ends were thereby created.

The sapping process postulated to cause wall recession and to create the dendritic tributaries may have occurred through the deterioration of exposed ground ice either by evaporation or by melting. Evaporation is more likely under present environmental conditions, but melting could have taken place under radically different conditions, if such existed, sometime in the past. Thus the process, if current, is best described as ground ice sapping, but, if older it may have involved ground water sapping [Milton, 1973].

$U$-shaped chutes high on trough walls look like features created on steep terrestrial slopes by dry debris avalanches. The fact that the chutes start fully developed at trough rims supports an origin through some mass movement process rather than fluvial erosion. The anastomosing pattern of ridges on wall slopes and on the flanks of intratrough ridges might also be the product of dry mass movements, because similar patterns, of much smaller scale to be sure, are created on steep slopes on the earth underlain by fine-grained unconsolidated materials, such as dune sand or loose soil, by removal of material through dry flowage. However, the resemblence of these anastomosing ridges to fluvially dissected terrestrial badland features suggests that running water also merits consideration as a possible genetic agent. If that is their origin, they are fossil forms.

Trough enlargement by wall recession has consumed large areas of the old cratered upland and may have continued for tens of millions to hundreds of millions of years. The freshness of some of the large slide scars on trough walls and of the piles of jumbled debris at their feet (Figure 2c) suggests an activity continuing essentially to the present.

Wall recession must have dumped huge quantities of rock debris onto trough floors, What has been the disposition of this material? The answer is constrained by the huge volume involved and by a vertical closure exceeding 3 $\mathrm{km}$ in at least one trough. Methods of moving the missing material up, down, or laterally need to be considered.

The geometrical configuration of troughs and the lack of visible ejecta around their margins speak strongly against explosion as the disposal agent. Eolian deflation, the other obvious means of moving material up and out, is so constrained by the huge size and geometry of the troughs and by the need to reduce all materials, including lag concentrates armoring the surface, to a fine grain size that deflation has probably played but a minor role at best. Furthermore, products of eolian activity such as dunes or characteristic wind-scoured forms are not seen on trough floors.

Surface transport by some flowing medium, e.g., water, cannot create closed troughs of the type shown in Figure $1 a$ and could have occurred only eastward from the belt of integrated troughs into an area of chaotic and fretted terrain. Burial of chaotic terrain by debris from the troughs would then be expected, unless the chaotic terrain is younger. In that case, water probably would not have been able to flow eastward because that area, not having yet collapsed to form chaotic terrain, would be higher than the trough floors. Some other route, which is not apparent, would thus have to be found. For these reasons it seems unlikely that water has had a major hand in carrying any significant amount of debris away from the area of troughed terrain. However, running water derived from melting ground ice, under climatic conditions vastly different from those now prevailing, might have played a role in removing material from the dendritic tributaries (Figure $4 a$ ), carving the badland topography of bounding slopes (Figures $4 a$ and $6 b$ ), and redistributing materials on the trough floors.

The most satisfactory disposition of the material missing from the troughs appears to be downward, by subsidence caused through removal of underlying support. The dissolution of rock materials is not an attractive possibility because of the probable lack of easily soluble substances and the need for a solvent. The melting of segregated ground ice is more attractive but suffers from quantitative qualifications. The planimetrically measured area of troughed terrain is $6 \times 10^{5} \mathrm{~km}^{2}$. If a mean trough depth of $3 \mathrm{~km}$ is assumed, the troughs represent a volume of $1.8 \times 10^{\circ} \mathrm{km}^{3}$. If the troughs were formed solely by subsidence caused by melting of segregated ground ice, some $1.6 \times 10^{6} \mathrm{~km}^{3}$ of water would have resulted. If all of Mars had a subsurface ice layer of a thickness equal to that required to form the troughs, it would 
represent $3.9 \times 10^{9} \mathrm{~km}^{3}$ of water. Rubey [1951] estimates that the total supply of water on the earth, in all forms, is $1.67 \times 10^{\circ} \mathrm{km}^{3}$, which is roughly 4.3 times that calculated above for Martian ground ice alone. Since the earth is volumetrically 7 times larger than Mars, the above figure would require that Mars has experienced a much greater proportionate degassing than the earth, which is difficult to believe. Abnormal developments of ground ice peripheral to the Nix Olympica volcanic field, a greater volatile content in Martian than in earthen materials [Fanale, 1971], or the possibility that the Martian ice is not water substance might afford ways of getting around this argument. Other arguments against ground ice deterioration as the principal mechanism of trough development are based on the need to develop segregated bodies of ice and the great depth of freezing required, as was summarized earlier [Sharp, 1973].

Proximity of troughed terrain to the largest young volcanic field on Mars suggests the possibility of magma withdrawal as a cause of subsidence. Volumetric relationships are favorable, because a single volcano such as Nix Olympica, if it is $23 \mathrm{~km}$ high as now thought, represents a greater volume of material than is missing from the troughs. Why the magma should move hundreds of kilometers laterally before being extruded is a more troubling question.

Another quantitatively adequate mechanism for creating the troughs would be lateral spreading of crustal plates. The character and configuration of the troughs cannot be explained satisfactorily by spreading alone, but, in combination with wall recession through some sapping process, an acceptable picture emerges. The spreading mechanism would provide an ever deepening and widening sump into which materials from the receding walls could be dumped by mass movement processes. Unless subduction zones exist on Mars, and signs of them have not yet been recognized, the lateral spreading hypothesis carries an interesting implication of planetary expansion.

Spreading is an exciting hypothesis and has major implications concerning the internal con- stitution and behavior of Mars. However, Carr [1973] argues against plate tectonics on Mars from volcanic relationships, and spreading is not a particularly satisfying explanation for the festoons of hollows west of the troughed terrain or of the chaotic and fretted terrains to the east and the north. Nonetheless, in our present state of ignorance concerning Mars, it is wise to keep all reasonable options open, and ground ice deterioration by evaporation or melting, magma withdrawal, and lateral spreading all appear capable of having played some role in creating the troughed terrain and its accompanying features.

Acknowledgment. So many people have played a part in contributing to the success of the Mariner 9 photographic mission that to enumerate any by name does disservice to others unmentioned. Those people who have had a role in this great scientific adventure will know it and hopefully will take satisfaction from the publication of the results.

\section{REFERENCES}

Blasius, K. B., A study of Martian topography by analytical photogrammetry, J. Geophys. Res., 78, this issue, 1973.

Carr, M. H., Volcanism on Mars, J. Geophys. Res., 78, this issue, 1973.

Fanale, F. P., History of martian volatiles: Implications for organic synthesis, Icarus, 15, 279, 1971.

Howell, J. V. (Ed.), Glossary of Geology and Related Earth Sciences, American Geological Institute, Washington, D.C., 1957.

McCauley, J. F., M. H. Carr, J. A. Cutts, W. K. Hartmann, Harold Masursky, D. J. Milton, R. P. Sharp, and D. E. Wilhelms, Preliminary Mariner 9 report on the geology of Mars, Icarus, 17, 289, 1972.

Milton, D. J., Water and processes of degradation in the Martian landscape, J. Geophys. Res., 78 , this issue, 1973.

Pettengill, G. H., A. E. E. Rogers, and I. I. Shapiro, Martian craters and a scarp as seen by radar, Science, 174, 1321, 1971.

Rubey, W. W., Geologic history of sea water, Geol. Soc. Amer. Bull., 62, 1111, 1951.

Sharp, R. P., Mars: Fretted and chaotic terrains, J. Geophys. Res., 78, this issue, 1973.

(Received January 4, 1973; revised March 15, 1973.) 